\title{
From Washington DC to Washington State: The Global Burden of Diseases Data Basis and the Political Economy of Global Health
}

\author{
Jean-Paul Gaudilliere and Camille Gasnier
}

\begin{abstract}
This chapter takes the origins, development and uses of the Global Burden of Disease database as lens to interrogate the political economy of global health, focusing on the intended logic of this massive accumulation and manipulation of epidemiological data, and the ways in which it informs the management of public health programs and activities. Following the GBD's journey from its first embodiment as a World Bank tool in the early 1990s to its present day development at the Institute for Health Metrics and Evaluation helps understand how epidemiological data travel to become actionable data, revealing the complex interactions between data gathering on political purpose and their effective uses (or non-use) in specific contexts. The GBD database was first conceived following an accounting logic closely linked with planning: by aggregating epidemiological as well as financial data, the aim was to achieve triage, i.e. balance health budgets and prioritize investments. Nevertheless, as we argue, the specific context of global health and its mode of government have given way to different and contrasting uses of the database. GBD data are now most referred to as indicator: in global "donors" discourses they figure as numerical pictures of suffering distribution across the globe and signs of emergency.
\end{abstract}

\section{Introduction}

Everybody paying a short visit to the Institute for Health Metrics and Evaluation's website can experience the wealth of data on diseases and on their impact world wide it offers. Indeed, this research center in global health, financed by the Gates Foundation and located in Seattle at the University of Washington, has elaborated an impressive database on the "Global Burden of Disease" made available through the site's interface. This software and its inexhaustible stock of charts and maps display

J.-P. Gaudilliere $(\bowtie) \cdot$ C. Gasnier

Cermes3, Inserm-EHESS, Paris, France

e-mail: Jean-Paul.GAUDILLIERE@cnrs.fr; camille.gasnier@ehess.fr 
Disease Adjusted Life Years (DALYs) lost world wide because of illness, enabling the comparison of the burden of illness across time, countries and/or pathologies.

The logic underlying this unique tool is that the "burden of diseases" is measurable at a global level based on the aggregation of local and national data collected through a network of hundreds of institutions and ten times as many collaborators; and that the impact of mortality, disability and risks can be reduced to one single standard unit: the years of life lost as a consequence of illness (what they call the "DALYs"). The GBD data basis thus provides a general equivalent for assessing the "global" impact of health disorders - both in the geographical and the epistemic meanings of the world global. This burden is massive amounting to hundreds of millions of years of life lost and IHME's implicit statement in making it visible is that such burden hinders the growth of the economy and the progress of social life on a grand scale.

But there is more to the GBD, specifically what it highlights is the question of non-communicable disorders and comorbidity. A long assumed vision of health in the global South stresses the importance of infectious disorders and a scenario of the epidemiological transition mimicking the twentieth century Northern history of the replacement of infectious diseases by chronic disorders. In contrast, the GBD data (Fig. 1) reveal that diseases in low- and middle-income countries are increasingly double in nature with infectious as well as non-communicable disorders like depression, cardiovascular or pollution related pathologies affecting the population of these countries and their people individually.

Who are the intended viewers of such data? To some extent they are research physicians and public health specialists but as IHME leadership and its sponsors explain in every presentation of the GBD: this is a tool for action (Gates 2013). Its envisioned users are in the first place donors, public or private, who must decide where to put their money and how to make the biggest difference in the future of the world's health with their investments. Underlying the display of objective health data is therefore an ethos of intervention and fast response to emergencies: "we" (the donors) are able to know what counts in global health, we are able to know how to prioritize actions, we are able to know how to evaluate outcomes and measure efficiency or performance.

Critical analysts and actors of global health alike have commented on the emergence of the GBD and its relations to global health (Adams 2016; Arnessen and Nord 1999; Birn 2009). One frequent thread of analysis is to approach it as the highly visible symbol of the transition from "international public health" to "global health". This transition has been analyzed as shifting power alliances, the World Health Organization and its member governments finding their dominant role challenged by a series of organizations that emerged in the 1990s (nongovernmental organizations, transnational corporations, influential foundations such as the Gates Foundation) (Brown et al. 2006; Muraskin 2005) to target specific emergencies (malaria, tuberculosis, HIV, and - rarely - non communicable diseases). This new political order was also reflected in a shift in practices, with the diffusion of new tools (standard programs for access to drugs and other technologies) sometimes 




Fig. 1 Representing the burden of accidents, infectious and non-communicable diseases worldwide

Source: IHME website, GBD Data visualizations, GBD compare, http://www.healthdata.org/datavisualization/gbd-compare, accessed November 10th, 2018

derived from corporations' management (standard procedures, accounting systems, performance indicators) (Reubi 2018).

Private initiative, markets, management and individual choices are the keywords of this new world of health beyond nation states; a world, which has often been identified as one more manifestation of the big neoliberal transformation of government originating in the 1980 s critical evaluation of Keynesian economic policies (Chorev 2007). Historians, anthropologists and sociologists have therefore regularly opposed global health and the postwar decades of international public health when development, nation-states, UN institutions and "health as a right" (as the WHO constitution proclaimed in 1946) dominated the landscape of health and population government, within and beyond the borders of nation-states (Brown et al. 2006; Chorev 2012; Randall 2016).

In this chapter, we use the GBD database as a lens to refine this contrast and interrogate the political economy of global health, focusing on the intended logic of this massive accumulation and manipulation of epidemiological data, and 
particularly on the question of triage ${ }^{1}$ as key issue and core practice in the management of public health programs and activities. The GBD's journey from the World Bank in the early 1990s to present day IHME helps understand how epidemiological data travel to become actionable data, revealing the complex interactions between data gathering on political purpose and their effective uses in specific contexts. Indeed, tracing the first GBD, the one, which surfaced in the World Development Report issued by the World Bank in 1993, the first programmatic document of this sort focusing on health, highlights the political goals grounding the invention of this new metrics whose main purpose was to allow the economic comparison and therefore the triage between different health interventions. In resonance with M. Morgan's analyses in the present book, we could say that the GBD database was first conceived following an accounting logic closely linked with planning: by aggregating epidemiological as well as financial data, the aim was to achieve triage, i.e. balance health budgets and prioritize investments. Nevertheless, as we argue, the specific context of global health and its mode of government have given way to different and contrasting uses of the database. GBD data as produced by the IHME are most referred to as indicators: in global "donors" discourses they figure as numerical pictures of suffering distribution across the globe and signs of emergency rather than tools for systematic comparison and prioritization. The journey from Washington to Seattle has therefore changed the nature of both the exercise and the data.

\section{DALYs as Global Metrics: The World Bank and Economic Triage}

The landmark in the World Bank sanitary turn was the publication of the 1993 World Development Report "Investing in health" (thereafter 1993 WDR), which made official and rationalized the Bank investments in health as decisive elements in its strategy to alleviate poverty. It thus departed from decades-long commitments to a vision of development centered on the building of infrastructures, on the rise of agriculture productivity and - when it came to deal with populations as such - on birth control (Devesh 1997; Ruger 2005; Staples 2006).

The change was not a sudden, crisis-like event, solely grounded in the new sanitary disorder of the time associated, for instance, with the dramatic impact of the AIDS epidemics. Rather, it had deep roots in 1980s internal debates on the meaning and targets of development, which remain to be properly mapped. For instance the Bank's Population, Health and Nutrition division priorities were deeply impacted by the 1970s and 1980s contestation of population control programs in the global

\footnotetext{
${ }^{1}$ Triage is a concept used so far by anthropologists to refer to "clinical triage", i. e. the local decisions regarding who will or not benefit from therapeutic and other interventions (see for instance Lachenal et al. 2014)
} 
South and the acknowledgment that some demographic transition was happening worldwide without much correlation with these programs. One critical aspect of these debates was the mounting importance of "human capital" as category for analysis and action as reflected in a wave of reports issued in the 1980s and 1990s (for instance Becker 1995). Human capital theories thus backed a gradual displacement of issues toward health, education and women empowerment reflected in the growing number of projects the PHN division launched and their shifting focus away from nutrition and population control.

A second dimension in the Bank's sanitary commitment was the complex relationship the shift maintains to structural adjustment policies. Investing in health did not officially contradict the latter's conditions for granting loans to nation-states caught in the debt crisis, namely the urgency of budget balancing and privatization. True, the Washington consensus singled out health and education as priorities. However, in practice, public investments in the social sector were very often severely cut as an effect of structural adjustment policies. Moreover, all along the 1980s cost recovery in the health system was a persistent motto in World Bank's reports and memos of understanding with countries (De Ferranti 1985). This provided the background for the famous 1987 Bamako declaration through which African countries expressed their willingness to engage in the generalization of patients' fees for hospitals services and drugs with the background motive that these fees would ease the financial burden of health institutions, provide rolling funds to improve supply and make "pseudo-clients" more responsible and attentive to the quality of what was provided. This agenda deeply backlashed and critiques escalated beyond the usual circles including public health circles and international organizations like WHO and UNICEF.

In the early 1990s World Bank officials knew it even if they disagreed about the interpretation of such developments, i.e. whether they should be considered as intrinsic flaws of the policy or signs of a misguided implantation by governments marginally interested in human capital development. A World Bank paper issued in 1995 thus tried to put adjustment's impacts on health into perspective, stating that countries that had undergone adjustment policies were allowed to spend more on health when adjustment ended and when their economy recovered, their spending on health growing faster than in countries that had not followed adjustment policies. ${ }^{2}$ The 1993 WDR was a de facto response as it offered an alternative by strongly endorsing the idea that markets cannot by themselves provide for health care, which is in most instances a public good. Investing in health thus meant in the first place strengthening public, meaning nation-states based, health systems.

Strong elements of continuity with structural adjustments nonetheless prevailed. In the Bank's eyes, public management of health was only thinkable if cost-effective, if performance was placed center-stage, if targets were carefully accounted and outcomes measured. The introduction of the Disability Adjusted Life Years (DALYs)

\footnotetext{
${ }^{2}$ World Bank Archives, Folder 392721, Memo Yazbeck A., Tan J-P, Tanzi V, "Public Spending on health in the 1980s: the impact of adjustment lending programs", Background Paper of the 1993 World Development Report, August 1995.
} 
was therefore not only a way to take into account health problems neglected using the usual mortality/morbidity statistics but also and more importantly the introduction of a measure, which could help balance problems and solutions, could for instance help decide whether, in a world of limited resources, tuberculosis chemotherapy was worth doing and putatively more effective than HIV prevention. Even if the DALYs were eventually criticized internally for their medical rather than economical nature - they could not help decide if states should invest in genetically improved crops or in health centers - the dream of a general equivalent, money-like, was not far away.

Calculating the DALYs implied aggregating mortality and morbidity data under the umbrella of lost years of life and therefore mobilized two different calculations. The first one amounted, for each disease category, to weighting the distribution of death numbers associated with age groups against the life expectancy specific to each country on the basis of coefficients factoring in the decreasing economic usefulness of people according to their age. The main novelty regarded the addition of a certain number of years of life lost due to "disability" based on a fractional equivalence between a year of normal life and a year of impaired life with the disease in question. The coefficients applied for each disease to compute the impact of disabilities, i.e. the number of years of life lost due to bad health were in fact defined by using an average of the answers of a small number of experts to adapted questions in surveys designed to reveal preferences: "You are a decision maker who has enough money to buy only one of two mutually exclusive health interventions. If you purchase intervention A, you will extend the life of 1000 healthy (non-disabled) individuals for exactly one year, at which point they will all die.... The alternative use of your scarce resources is intervention B, with which you can extend the life of $n$ individuals with a particular disabling condition for one year. If you do not buy intervention B, they will all die today; if you do purchase intervention B, they will die at the end of exactly one year." (Arnessen and Nord 1999, p. 1424). Experts had then to choose the value for $n$ that would make them indifferent between the two programmes (Murray et al. 2002).

Following the publication of the 1993 report, the calculus of DALYs has been much discussed including the ways in which the GBD numbers incorporate a productivity-based understanding of the value of life or a quantified understanding of how valuable, how normal, is a year of life with tuberculosis, diabetes or cancer. Bringing the impact of disease down to a single indicator based on age, gender, the disability situation and the moment when the disease began was justified by the need to build a comparison tool allowing decision makers to choose their interventions by comparing the incomparable, by evaluating, for instance, the difference between the cost of one year of life for a child suffering of vitamin deficiency and cost of one year of survival for a 50-year-old with cancer. Put it differently, the DALYs were an attempt to seize all kinds of suffering in a commensurable way, in order to compare the effects of very different health interventions and choose the most efficient ones in budget constraints contexts, i.e. to try to optimise investments in health by choosing the interventions that would be the most effective in relieving the "burden" of suffering. In resonance with M. Morgan's analyses in the present 
book, the invention of the GBD could be understood as accounting data, data linked to the government's need to monitor the economy in a constraint budget, to arbitrate between different social investments (others than health, also education, see M. Morgan's chapter) and to evaluate and optimize the returns.

From this point of view, the DALY works in a similar way to the QALY (Quality Adjusted Life Years) in health economics. In fact, the discussion of DALYs in the 1990s was similar to the numerous debates about QALYs, their advantages and limitations; for example, targeting the coefficients used to give the deaths of children or old persons less weight (Gavin 2002), or the arbitrary nature of the assessments regarding the value of one year of life with various disabilities or the value of impaired functioning due to a disease, as if human misery, "evaluations of severity and its cost [could] be validly standardized across different societies, social classes, age cohorts, genders, ethnicities and occupational groups" (A. and J. Kleinman 1996). More important for this paper is however the connection the 1993 report made between the DALYs and the measurement of cost-effectiveness. This was a central ingredient in the valorization of the GBD as basis for triage. This linkage has been overlooked since - for reasons discussed below - it disappeared from the exercise when the GBD machinery moved from the World Bank/Harvard/WHO complex to the Gates/IHME nexus.

The calculus of DALYs was actually combined with a general evaluation of performance in national health systems. For the poorest countries, the recommendation was to stop financing high-technology hospitals and expensive care infrastructure, only of benefit to the middle and upper classes, and to privilege interventions that would meet the needs of the most destitute, populations "at risk", less because of their peculiar exposure to pathogens than because of their social and economic vulnerability. Hence, the World Bank experts recommended reorganizing protection by defining a publicly offered and freely accessible basic system of care (the only one for which direct, centralized and evaluable action was possible).

One should not be mistaken, the point was not to leave out private actors, on the contrary, but to make a critical distinction between basic and more individual needs, between countries rich enough to cover costs, whatever the mechanism (taxation, insurance or patients' contribution) without drastic triage and low- and middleincome countries with very limited resources, where most households were not in a position to provide for their health needs, where triage was operating de facto, without much rationalization, favouring the urban middle class, and where the public provision of an "essential package" of interventions (through both public and private, first of all NGOs, services) was indispensable: "Perhaps the most fundamental problem facing governments is simply how to make choices about health care. Too often, government policy has concentrated on providing as much health care as possible to as many people as possible, with too little attention to other issues. If governments are to finance a package of public health measures and clinical services, there must be a way to choose which services belong in the package and which will be left out." (World Bank 1993 p. 59).

This plea for targeted investments was delineated in a much more detailed and prescriptive way with the selection of 47 interventions for which the Bank panels of 
economists and health specialists computed costs and numbers of years of life saved in order to provide cost-effectiveness ratio. This complex operation actually started before the writing of the 1993 WDR, namely in 1988, with the establishment of a "Disease Control Priorities" (DCP) working group within the PHN division of the Bank whose initial aim was to develop new tools for measuring the effectiveness (rather than the monetary benefits) of health investments. ${ }^{3}$

The DCP project relied on another kind of triage to define the rationale for government's involvement in health, not only in prevention but also in curative services. Indeed, published as background material to the WDR report, the DCP working group final document relied on the attempts by panels gathering epidemiologists and economists working on one pathology, i.e. tuberculosis, or one medical issue, i.e. mental health, to assess legitimate interventions in their field, gather all available economic evidence on their costs and outcomes under optimal conditions and when possible - provide numbers for the cost per DALY avoided. These numbers were then used to rank interventions according to their effectiveness. A major result was that - in contrast - to the classical divide health economists were making between prevention and treatment with the former considered as "public good" due to the importance of externalities and the impossibility to accrue individual benefits to a putative buyer, economic legitimacy crossed the line with highly cost-effective clinical intervention such as tuberculosis chemotherapy and poorly cost-effective preventive intervention such as water sanitation (Fig. 2).

The final outcome of this ranking effort was the proposition of an "essential package of health services" in developing countries. Beyond effectiveness expressed in terms of cost for one DALY avoided, overall spending was critical in the selection: World Bank experts estimated unrealistic to bet on a massive increase of public expenditures in low- and middle-income countries even if they spend much less than developed ones in proportion of their GNP. The essential package was thus limited to a doubling of what low-income countries were already spending to reach the level of $\$ 12$ per person per year. The package prolonged and provided new legitimacy to existing priorities like immunization, STD treatment, prenatal care, family planning or Aids prevention. Decisive novelty resided in a few items in the category of non communicable diseases prevention and clinical treatment: tobacco control or the more important "limited care" cluster focusing on the treatment of skin allergies and injuries on the one hand, access to medications for pain relief, diabetes, hypertension, and tuberculosis on the other hand (Bobadilla et al. 1994).

Cost-effectiveness and performance - the values imbedded in the first GBD as well as the associated expectations for an economically rationalized triage to some extent confirm the neo-liberal scenario with one qualification, which is to recognize that privatisation of health services was only marginally the issue while triage was the fundamental one. As C. Murray, the man who had so strongly pushed for the creation of the GBD summarized: «Decision-makers who allocate resources to

\footnotetext{
${ }^{3}$ World Bank Archives, Folder 19831130, de Ferranti, « Sector financing an overview of the issues », Draft Population Health \& Nutrition Paper, November 30th, 1983.
} 


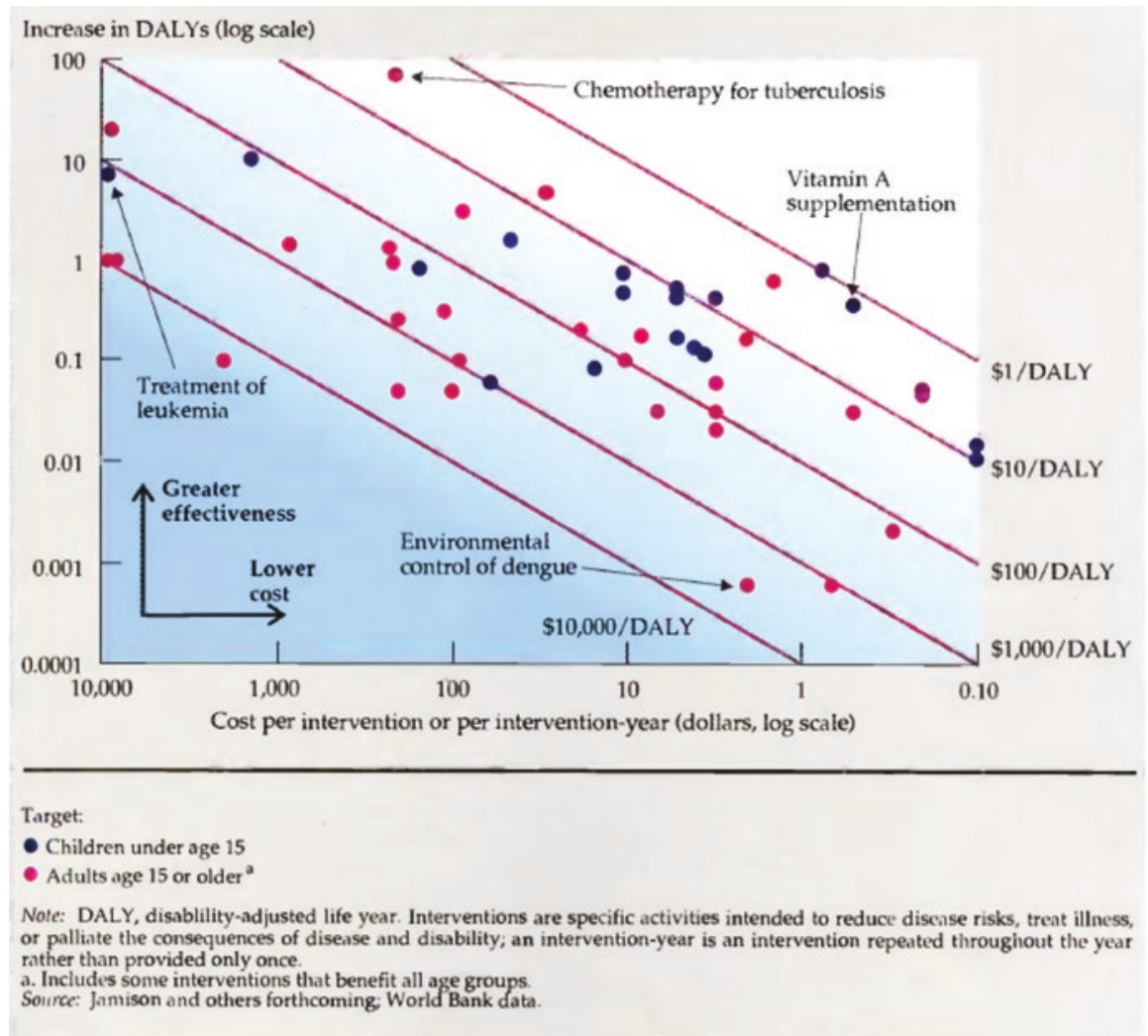

Fig. 2 Benefits and costs of forty-seven health interventions Source: Courtesy of the World Bank (Jamison et al. 1993)

competing health programs must choose between the relative importance of different health outcomes such as mortality reduction or disability prevention. Because money is one-dimensional, the allocation of resources between programs defines a set of relative weights for different health outcomes. The only exception to this is in a completely free market for health care where such decisions between competing health programs are not made by a central authority but by individuals, one health problem at a time. » (Murray 1994).

The logic of economic triage and package design thus exemplify the accounting nature of the DALYs calculus. The comparison of interventions for their costeffectiveness and their putative inclusion in a public package of services operated within the framework of an imaginary budget balancing exercise, namely a search for the "best" equilibrium between "inputs" (financial resources, most often combining state and donors) and "outputs" (the costs of selected interventions) that may include increasing inputs but most often meant adjusting outputs to preset levels of 
inputs (see below the example of Bangladesh). Thus, rather than privatizing, states were now mandated to focus on investment performance. They were invited to enter what may be described as an audit culture (Power 1997) based on the use of a whole new range of evaluation and ranking instruments (Gaudillière 2014, 2016).

It was therefore not mere rhetoric when the authors of the report made an unexpected link with the old WHO primary health care strategy, explaining in their overview of the report that: "Provision of cost-effective health services to the poor is an affective and socially acceptable approach to poverty reduction. Most countries view access to basic health care as a human right. This perspective is embodied in the goal "Health for all by the year 2000" of the conference held by the WHO and UNICEF at Alma-Ata in 1978, which launched today's primary health care movement. Private markets will not give the poor adequate access to essential clinical services or the insurance often needed to access such services. Public finance of essential health services is thus justified to alleviate poverty. Such public funding can take several forms: subsidies to private providers and NGOs that serve the poor; vouchers that the poor can take to a provider of their choice; and free or below-cost delivery of public services to the poor." (1993 WDR, p. 5).

\section{Health System Data and Political Triage: Primary Health Care at WHO}

In its own way, i.e. the equation of primary health care with an essential package of intervention, the World Bank homage highlights one of the main elements of continuity between global health and international public health as typified in the 1978 Alma Ata strategy, namely the politics of scarcity and the permanence of triage. The Primary Health Care (PHC) strategy looked at health as human basic need whose fulfillment could not be thought of and worked out in isolation from other "sectors" of development. This had two major sequences.

The first one was that health was an object of planning. Late 1970s and early 1980s WHO texts on PHC thus endlessly repeat that PHC is a national strategy that presupposes public investments that need to be coordinated in a plan for the entire country and for "all the people" with a special view on those at the periphery, the most needy rural populations. The second element was that health had to be integrated in a general planning balancing investments in the health and other sectors with an eye on the multiple links between the various ingredients of progress. Deemed of special importance within this perspective were "boundary" questions of food and nutrition, water supply and sanitation, family planning and education policies.

PHC targeted "appropriate, affordable and acceptable technologies" and the establishment of "local" and "integrated" centers addressing "basic needs". The critical question was therefore how would such needs be selected and become ingre- 
dients in the national health planning. The first response was that basic needs should be defined on the basis of epidemiological and public health knowledge mobilized by experts. The second and most forgotten response was to admit that the selection of "basic needs" was in the first place a political choice and that communities should - at least in the discourse - be granted a say.

Unsurprisingly political triage of the first sort dominated. Rooted in a long process of internal consultation involving all regional offices of the health organization - and in spite of a lack of transparency regarding the criteria and tools to achieve selection - the conference of Alma Ata ended with this list of targets: "education concerning prevailing health problems and the methods of identifying, preventing and controlling them; promotion of food supply and proper nutrition; an adequate supply of safe water, and basic sanitation; maternal and child health care, including family planning; immunization against the major infectious diseases; prevention and control of locally endemic diseases; appropriate treatment of common diseases and injuries; promotion of mental health; and a provision of essential drugs."

Political triage however did not imply an absence of data and numbers but these were epidemiological in the first place but not exclusively. Long before WHO and the World Bank started to collaborate (with all the tensions some participants have highlighted) in the making of the GBD, WHO and the Bank's PHN division had inaugurated exchanges of information, personnel and launched common ventures. Alma Ata was in this respect a turning point: from the World Bank perspective because it made its director and personnel consider that something new was happening at WHO that seized health as a system, linked to infrastructures and to other areas of development; on the later side because the Bank appeared not only as a resource for the funding of programs like sanitation projects but also as a source of expertise in the increasingly acrimonious debate on the feasibility of the PHC strategy, its broadness and the alleged need for a more selective approach. WHO thus sought WB help in defining a strategy for financing PHC, obtained WB collaboration for several new programs, including tropical disease research, maternal and reproductive health, extended immunization with the consequence that both institutions engaged in regular almost yearly strategic consultations. One specific dimension of this emerging common ground was the problem of health systems evaluation. Soon after Alma Ata, the WHO Director General started to look for Bank's knowhow in the evaluation of development projects and system analysis having in view WHO ability to help nation states in the design of systemic reforms rather than vertical, operation or disease oriented projects. This resulted in the creation of a dedicated team, which started to collect data and produced in 1980 the first reference document on 'health systems' indicators and evaluation, which ideally included non-epidemiological data on budget, personnel, buildings, access to care and coverage. ${ }^{4}$

\footnotetext{
${ }^{4} \mathrm{WHO}$ archives, draft memo «Indicators for monitoring progress toward 'Health for all' », 10 July 1980.
} 


\section{Missing and Alternative Numbers: The Low Visibility of DALY-Based Triage}

Once the intimate relations between the GBD and economic triage as well as their difference with political triage and its associated data are acknowledged, the question becomes that of whether this unique global metrics is actuality used by donors or public health authorities. Such use has been postulated but rarely shown. It is true that DALYs figure in many discourses on global health emergencies or programs but this is in most instances as legitimizing argument, in isolation, with no connection to cost-effectiveness and without any significant comparison across interventions or diseases.

A good example is that of tuberculosis chemotherapy. The disease and the treatment figured prominently in the 1993 WDR as it appeared as one of the most costefficient intervention with a ratio a little above $\$ 1$ per DALY avoided. The calculation originated in a nation-wide experimentation of a new regimen based on the shortcourse administration of standard antibiotics association conducted by the International Union Against Tuberculosis and Lung Disease (IUATLD) in Tanzania (and later in Malawi and Bostwana) during the 1980s (Gaudilliere et al. forthcoming). Employing initially a vintage regimen that combined streptomycin, isoniazid and thiacetazone, the project focused on operational improvements, care, and epidemiology to give existing regimens traction throughout the country. Examining what IUATLD introduced, we can imagine what was lacking before: systematic reporting of new cases and treatment was mandated; diagnosis through sputum microscopy rather than X-ray - was made the compulsory standard; drugs were provided free of charge.

IUATLD experts kept an eager eye on efficiency of the program. Such efficiency was of course organizational, i.e. choosing the right protocol and building proper institutions. With the consequence that treatment failure would still be blamed on the non-compliant patient, while social conditions that drive epidemics and complicate therapy drop from the radar. The issue of strains resistant to antibiotics and therefore of drug sensitivity testing was given low priority when developing the NTLP (National Tuberculosis and Leprosy Program) along IUATLD lines. While diagnostic and treatment capacities with regards to bacteriologically positive cases were greatly expanded, diagnostic facilities in relation to drug sensitivity testing remained insufficient with one functional sputum culture laboratory throughout the whole period 1979-1988. Efficiency was not only a problem of epidemiology. It was also a matter of costs and choice of priorities; for instance aiming for a cure rate above $90 \%$ was considered useless at it would disproportionately increase costs and therefore should be avoided. ${ }^{5}$ Cost efficiency was thus aimed at before the Tanzanian TB program got picked up in the World Bank calculus of DCP. Such interest resulted

\footnotetext{
${ }^{5}$ ERC GLOBHEALTH archives (Cermes3, Paris), Karel Styblo papers, Progress report «Results of the NTLP after the First Ten Years», June 1988.
} 
in joint publications of IUATLD main expert Karel Styblo and of Christopher Murray, the architect of GBD, who in those days worked for Harvard University's Center for Population Studies (Murray et al. 1991a, b). Styblo and Murray combined public health epidemiology with economic analysis. Their evaluation of costeffectiveness of short course therapy rested not just on curing more patients than standard therapy but also on the projected number of deaths averted or treatment costs avoided in future population.

Towards the end of the 1980s the Union project thus changed context and became the basis of a global strategy. The World Bank, from 1991, initiated a large-scale trial of the same regimen in China. The WHO, changing course after two decades of relative neglect for tuberculosis care, declared TB a global emergency in 1993. It used the IUATLD trials as examples and condensed the approach into the Directly Observed Treatment Short-course (DOTS) strategy that it put in practice from 1995 onward. As defined at the time, DOTS consisted in five elements deemed critical for success: the existence of a national program with significant political priority, the reliance on passive detection rather than active search for patients, bacteriological diagnosis, proper supply of drugs and delivery free of charge, and what had strongly come to the fore in the shift from trial to strategy: directly observed treatment meaning a form of ambulatory treatment such that patients would receive and absorb the drugs under the supervision of health personnel or of dedicated community workers. Advocating for DOTS in the mid-1990s, WHO made an abundant use of the 1993 World Bank cost-effectiveness calculus but dissociated what concerned tuberculosis chemotherapy from the entire discussion about an essential package of care and from the comparison with other interventions and their ranking. The \$1 per DALY avoided was singled out and aligned with more clinical and epidemiological numbers like the regimen $90 \%$ efficiency or the projected numbers of deaths averted.

This did not imply that the logic of economic triage did not play a role in the 1990s global government of tuberculosis. In 1997 the World Bank reached an agreement with the Government of India, providing the latter $\$ 100$ millions in order to reorganize its National Tuberculosis Program and implement the DOTS strategy. Launched in the 1960s the latter was the first program of its sort in developing countries and during the years WHO engaged in the PHC strategy, it played an exemplary role there. In the mid-1990s, when India began negotiations with the World Bank to get funding for a new programme, WHO and World Bank experts' evaluating this legacy were barely impressed: the Indian old program had certainly suffered from "serious lack of funds", but, according to the World Bank experts, it had been badly designed and organized with "insufficient trained staff $(\ldots)$, reliance on X-ray instead of sputum analysis for diagnosis (...), with a proliferation of drug regimens (...), a private sector which treat[ed] over 50\% of new TB with an extraordinary variety of ineffective and potentially harmful drug regimens (...), a lack of quality control and regular supply of drugs (...), a reluctance of service providers to give adequate information to patients because of stigma (...), a poor recording and monitoring system (...) a lack of quality control of laboratory results." (World Bank 1997). In other 
words, the programme was the opposite of the DOTS strategy, which was to be implemented on a massive scale, i.e., during the first 5 years, in 102 districts with a total population of 270 million persons.

Performance was not defined from the point of view of costs, which was done beforehand by calculating the total amount of the contract based on the average cost of chemotherapeutic treatment. The target criteria selected by the World Bank and the Indian Ministry of Health were medical and epidemiological: number of persons detected and treated (2 millions) and success rate of the cure (85\%, where success is equal to the disappearance of TB-bacteria from examined sputum). All of this made it possible to anticipate a significant reduction in the incidence of tuberculosis.

Health data were however also proxys for another kind of performance, this time an administrative one, as is seen in the list of the specific risks of the programme identified by the World Bank experts, which were the risks of: difficulties in persuading providers and patients to accept the practice of directly observed treatment and the rigorous features of the DOTS strategy; poorly administered short-course chemotherapy and poor quality anti-TB drugs, which would increase the probabilities of developing drug resistance; the inability of the Central and State TB Cells to provide the leadership and services required to ensure proper implementation of the programme; an uneven supply of drugs combined with the availability of large quantities of drugs which could be misused, especially in light of "the spotty record of drug deliveries in India". (World Bank 2006).

Many development economists, including within the World Bank, however share the vision that GBD and the DALYs are not proper economic instruments since they favor an "internal" public health orientation that allow for comparison between diseases or interventions but do not provide for any rational for core economic questions like the level of investments, the allocations of resources between health and other social and economic sectors, the kind of care provision that can be left to the market; all questions central to the management of national health systems. As a consequence there is a low visibility of DALYs-based cost-effectiveness calculus even in the Bank's own assessment of health related investments and packages.

A good illustration of this is the late 1990s negotiation of health system reform in Bangladesh, during which the design of the basic package of essential services provided by the state took place without any mobilization of the kind of ranking involved in the 1993 WDR even if the process started with the \$12 package proposed in the 1993 WDR report. The donors' mission and the local authorities had to take into account the fact that the Ministry of Health budget amounted to spending in the range of $\$ 3,5$ per capita only. A technical group gathering practitioners, public health specialists and health authorities was gathered to select the interventions falling into four priorities areas: child health, reproductive health and population, communicable diseases, simple curative care whose costs would be computed with the help of an economist paid by WHO. Assuming that no significant increase of resources was politically feasible, triage to align the package with the $\$ 3,5$ ceiling was the preparation team's next task. The technique used was not only cost- 
effectiveness ranking but a scoring of each intervention involving five criteria for triage: costs, provision feasibility, potential health impact, burden of disease and economic status (whether the intervention could be considered as public good and the importance of its externalities). The dominance of general economic criteria in the process was reinforced in the last stage of triage since eliminating interventions from the package through scoring proved very difficult: it failed meeting the $\$ 3,5$ target, leaving a deficit in the range of $15 \%$. In order not to stall the negotiations with the donors and secure the help of World Bank, USAID and Northern Europe aid agencies, the preparation team finally agreed to draw a balanced "contingency plan", which the Bengali considered as a first step. As the World Bank expert participating in the negotiations later explained: "while (cost-effectiveness) is an economic evaluation tool, public health specialists, much more so than economists, swear by it as a primary prioritization tool." (Yazbek 2002).

One must add that the use of DALYs as instrument of economic triage has also been impaired by the difficulties associated with data collection for comparison on such grand scale and the recurrence of doubts or mistrust originating in its "missing" numbers and the complexity of the modeling involved in finding "proxys". This may be illustrated with one of the major outcomes of GBD, which has been to give an unprecedented visibility to mental health and psychic disorders in the global South. In a recent study of global mental health in West-Africa Anne Lovell has thus shown that for most of the region the numbers available in the GBD did not rely on local studies, did not mobilize the data originating in the operations of local health institutions, but originated in a complex set of correlations between the burden of mental health disorders and various epidemiological, social and economical variables worked out in countries benefiting from more reliable statistics (Lovell forthcoming).

The absence of policy-oriented use of the GBD of the kind that was expected at its origins doesn't mean that the GBD database is no longer conceived as data that could be used to enhance political decision-making relying on cost effectiveness analysis. Indeed, in spite of its infrequent use, the Disease Control Priorities project is still alive, at least as a modeling enterprise. In the mid-2000s, in parallel with its investment in IHME, the Gates Foundation started funding a follow up of the 1993 WDR, helping Dean Jamison and his colleagues produce a second DCP, and more recently a third DCP. The latter, based on complex computer simulation models and selecting 93 interventions and updating their ranking, has become part of mounting contemporary debates about "universal health coverage". Thus, economic triage based on DALYs has not disappeared, the irony being that it now finds renewal in debates regarding "universal health coverage", which reveals strong stands in favor of public investments compared to private markets but also deep tensions regarding universality understood as access for all but also universality understood as care for all health "needs", thus acknowledging although in an oblique manner the importance of political triage. 


\section{Conclusion}

After its birth in between Washington DC and Harvard University, the GBD went through a period of difficult existence as its production was no longer supported by WHO or the World Bank (Smith 2015). It was finally rescued in 2007 when the Gates Foundation decided to fund the enterprise and have it relocated in Seattle at IHME, an independent institute at the University of Washington. The enterprise then took the form presented above, that of a global epidemiological data-basis whose connections with health economics is scant, namely embedded in the history of the DALYs on the one hand, acknowledged with the inclusion in the IHME data basis of financial information regarding global health investments on the other hand, thus leaving out of the scene the links between the two, i.e. cost-effectiveness, intervention ranking and economic triage.

There is no doubt that data and the GBD machinery travelled from Washington (DC) to Washington (State), but can this journey account for the changing epistemic status of the enterprise, for the fact that economics and triage have been put at arms' length? The response is certainly positive if the journey is considered not as a geographical displacement but as a shift from one social world to another. GBD moved from being strongly associated with a key financial institution whose main activity is the triage of development related loans to being inserted in one of the hotspots of global health academic life.

The move has been discussed as a consequence of personal tensions between its initiator, C. Murray, and other players in global epidemiology, or as an effect of WHO bureaucracy and entrenchment in outdated data production (Smith 2015). Given the origins and meaning of the first GBD, a much more critical question is that of the World Bank not following up and integrating the GBD in its operations; of the World Bank not producing any second WDR on health after 1993. As suggested in this paper, in so far as a non-event can be interpreted, this non-investment has deep roots in the tensions underlying the genesis of the tool.

In her chapter "The Datum in Context: Measuring Frameworks, Data Series and the Journeys of Individual Datums" of this volume, Morgan stresses the multiplicity of data sets economists have designed emphasizing the importance of their internal logic, i.e. the relationship between bits and whole. She accordingly distinguishes the accounting logic typical of highly integrated data sets like the matrix of national economies and the indicators logic of loosely articulated sets of numbers like those associated with the Millennium Development Goals. The difference resonates with the distinction we make between the uses of the GBD as instrument of economic triage, central to the design of packages, the comparison and optimization of investments on the basis of their cost-effectiveness on the one hand, and the uses of GBD data in an isolated manner, as measurement of the worth of isolated interventions or projects in order to legitimize choices made on the basis of other metrics and/or criteria be they epidemiological, organizational or social. The $\$ 12$ package of the 1993 WDR report is emblematic of the accounting mode; WHO use of DALYs to 
argue for the rationality of the DOTS strategy for controlling tuberculosis fits the indicator mode. Typical of the problematic life of the accounting mode is the fact that it is also in such a mode that the Gates Foundation uses the GBD. Analyzing the Bloomberg Initiative, a philanthropist association spearheaded by the Bloomberg and Gates Foundations and aiming at reducing tobacco use, David Reubi quotes an epidemiologist involved in the Initiative, explaining how Bill Gates relied on Murray's work on the GBD to design the Initiative. (Reubi 2018).

Morgan's perspective is also that these contrasted kinds of data strongly constrain their possible uses and ability to travel. Accordingly, the GBD data, originally elaborated to compare cost effective health interventions and choose the most efficient one, are nowadays more often used as isolated indicators of the geographical distribution of suffering worldwide and linked to different causes rather than as accounting data with strong relations to the whole, here economic growth. The trajectory of the GBD however reveals less direct relationship between kinds of data and political decision-making, more complex patterns for which the question of context in general, the political economy of global health in particular can't be avoided. This is quite obvious when considering the rise of triage based on economic data and performance assessment and the many ways in which this form of calculus and resource allocation contrasts the political triage of international public health and its logic of health needs. What this paper shows is that a simple reading of contemporary economic triage either as consequence of data sets design or as straightforward manifestation of the neo-liberal paradigm can't account for GBD uses and non-uses. Multiple political economies of health as well as heterogeneous institutional configurations were and are at stake resulting in differentiated modes of accounting as the difference between the vision of health financing underlying the 1993 WDR and the more neo-liberal one the "Population Health and Nutrition" division of the World Bank developed in the mid-1980s.

An important factor to be considered is thus the fact that the global health field in which the World Bank operates since the late 1990s is no longer that of nationstates "planning" development and making budget allocations. The global health world is a world of competing "causes" and vertical programs, which do not, or only marginally, target systems. It therefore does not require broad comparisons of interventions across the health sector, not even speaking of comparisons across the entire spectrum of development targets. Even the World Bank, that invented the GBD and that is supposed to be a development bank that invests in health systems strengthening, also massively targets vertical programs, mimicking its competing partners of "transnational humanitarianism" (Fassin, 2011). In fact, the global health movement at large doesn't seem to need a global metrics such as the GBD, its players being much more interested in indicators, that is to say data informing projects' symbolic and technical performance (David 2018).

Acknowledgements The research grounding this paper was conducted within the framework of the research project GLOBHEALTH (From International to Global: Knowledge, Diseases and the Postwar Governement of Health) funded by the European Research Council Grant 340510. 


\section{References}

Adams, Vincanne. 2016. Metrics and the Global Sovereign. In Metrics: What Count in Global Health, ed. V. Adams. Durham: Duke University Press.

Arnessen, Theo, and E. Nord. 1999. The Value of DALY Life: Problems with Ethics and Validity of Disability Adjusted Life Years. British Medical Journal 319 (7222): 1423-1425.

Becker, Gary. 1995. Human Capital and Poverty Alleviation, World Bank Working Papers. Washington, DC: The World Bank:.

Birn, Ann-Emmanuelle. 2009. The Stages of International (Global) Health: History of Successes or Successes of History. Global Public Health 4 (1): 50-68.

Bobadilla Jose-Luis, Cowley Peter, Musgrove Phillip and Helen Saxenian. 1994. The Essential Package of Health Services in Developing Countries, World Bank Report 1993 Background Papers Series Number 1. Washington, DC: The World Bank.

Brown Theodor, Cueto Marcos, and Fee Elizabeth. 2006. The World Health Organization and the Transition from 'International' to 'Global' Public Health. American Journal of Public Health 96 (1): 62-72.

Chorev, Nitsan. 2007. Remaking US Trade Policy. From Protectionism to Globalization. Ithaca: Cornell University Press.

— 2012. The World Health Organization Between North and South. Ithaca: Cornell University Press.

De Ferranti, David. 1985. Paying for Health Services In Developing Countries. An Overview, World Bank Staff Working Papers Number 721. Washington, DC: The World Bank.

Devesh, Kapur, John P. Lewis, and Richard C. Webb. 1997. The World Bank. Its First Half a Century. Washington, DC: The Brookings Institution.

Fassin, Didier. 2011. Humanitarian Reason: A Moral History of the Present. Berkeley: University of California Press.

Gates, William. 2013. How We Measure Impact to Improve Lives. Bill and Melinda Gates Foundation, January 29th. http://gatesfoundation.org/Who-We-Are/Resources-and-Media/ Annual-Letters-List/Annual-Letter-2013.

Gaudillière, Jean-Paul. 2014. « De la santé publique internationale à la santé globale: l'OMS, la Banque Mondiale et le gouvernement des thérapies chimiques ». In Le gouvernement des sciences à l'échelle globale, D. Pestre (dir.), 65-96. Paris: La Découverte.

—. 2016. «Un nouvel ordre sanitaire international ? Performance, néolibéralisme et outils du gouvernement médico-économique ». Ecologie \& politique, 2016/1 (52): 107-124.

Gaudillière, Jean-Paul, Christoph Gradmann, and Andrew McDowell. forthcoming. " The not so distant past, tuberculosis and the DOTS challenge ». In From International to Global Health, ed. C. Beaudevin et al. Manchester University Press.

Gavin, Yamey. 2002. Have the Latest Reforms Reversed WHO's Decline? British Medical Journal 325 (7372): 1107-1112.

Jamison, D.T., W.H. Mosley, A.R. Measham, and J.L. Bobadilla, eds. 1993. Disase Control Priorities in Developing Countries. New York: Oxford University Press.

Kleinman, Arthur. 1996. The appeal of Experience; The Dismay of Images: Cultural Appropriations of Suffering in Our Times. Daedalus 125 (1): 1-23.

Lachenal Guillaume, Lefève Céline, Nguyen Vinh Kim. 2014. La médecine du tri. Histoire, éthique, anthropologie. PUF, coll. Science histoire et société.

Lovell, Anne. forthcoming. Global Mental Health Metrics in Sub-Saharan Africa: So 'Poor Numbers' Matter for Public Health?.

Muraskin, William. 2005. Crusade to Immunize the World's Children. Los Angeles: USC Marshall - Global Biobusiness Initiative.

Murray, Christopher. 1994. Quantifying the Burden of Diseases: The Technical Basis for DisabilityAdjusted-Life-Years. The Bulletin of WHO 72 (3): 429-445.

Murray, Christopher J., Styblo Karel, and Rouillon Annick. 1991a. Tuberculosis in Developing Countries: Burden, Intervention and Cost. Bulletin International Union Tuberculosis 65 (1): $6-24$. 
Murray, Chiristopher J., et al. 1991b. Cost Effectiveness of Chemotherapy for Pulmonary Tuberculosis in Three Sub-Saharan African Countries. The Lancet 338 (8778): 1305-1308.

Murray, Christopher J., et al. 2002. Summary Measures of Population Health. Concepts, Ethics, Measurement and Applications. Geneva: WHO.

Power, Michael. 1997. The Audit Society. Rituals of verification. Oxford: Oxford University Press. Randall, Packard. 2016. A History of Global Health. Interventions into the Lifes of Other Peoples. Baltimore: Johns Hopkins University Press.

Reubi, David. 2018. Epidemiological Accountability: Philanthropists, Global Health and the Audit of Saving Lives. Economy and Society, in press.

Ruger, Jennifer P. 2005. The Changing Role of the World Bank in Global Health. American Journal of Public Health 95 (1): 60-70.

Staples, Amy S. 2006. The Birth of Development. Kent: Kent State University Press.

Smith, Jeremy. (2015). Epic measures. One doctor, Epic Measures. One Doctor, Seven Billion Patients, New York: Harper-Collins.

World Bank. 1993. World Development Report 1993 Investing in Health. New York: Oxford University Press.

- 1997. Staff Appraisal Report. India. Proposed Tuberculosis Control Project, Rapport No. 15894-IN, 6 January.

- 2006. Implementation Completion Report on a Credit in the Amount of US\$96.7 Million to India for a Tuberculosis Control Project. Report No: 34692, 29 June.

Yazbeck, Abdo S. 2002. An Idiot's Guide to Prioritization in the Health Sector, HNP Discussion Paper. Washington, DC: The World Bank.

Jean-Paul Gaudillière is a Senior Researcher at the Institut National de la Santé et de la Recherche Médicale and Coordinator of the ERC project "From International to Global: Knowledge, Diseases and the Postwar Government of Health". His recent work focuses on the history of pharmaceutical innovation and the uses of drugs on the one hand and the dynamics of health globalization after World War II on the other hand. Amongst others, he has coedited, with Volker Hess, Ways of Regulating Drugs in the 19th and 20th Centuries (Basinkstokes, RoutledgePalgrave); with U. Thoms, The Development of Scientific Marketing in the Twentieth Century: Research for Sales in the Pharmaceutical Industry (New York, Pickering \& Chatto, 2015); and, with L. Pordie, Industrial Ayurveda: Drug Discovery, Reformulation and the Market (Asian Medicine, vol. 9, 2014-2015).

Camille Gasnier is a Sociologist. She has been working on norms and the new forms of health and environmental management in the private sector. She is currently Postdoctoral Fellow at Cermes3 within the framework of the ERC project "From International to Global: Knowledge, Diseases and the Postwar Government of Health".

Open Access This chapter is licensed under the terms of the Creative Commons Attribution 4.0 International License (http://creativecommons.org/licenses/by/4.0/), which permits use, sharing, adaptation, distribution and reproduction in any medium or format, as long as you give appropriate credit to the original author(s) and the source, provide a link to the Creative Commons license and indicate if changes were made.

The images or other third party material in this chapter are included in the chapter's Creative Commons license, unless indicated otherwise in a credit line to the material. If material is not included in the chapter's Creative Commons license and your intended use is not permitted by statutory regulation or exceeds the permitted use, you will need to obtain permission directly from the copyright holder.



